\section{Diarrhoea and Vomiting}

SIR,-The epidemics of " $D$. and V.," such as we used to have towards the end of every summer when I first went to Guy's Hospital as a student in 1924, are now fairly rare ; and when outbreaks or odd cases do arise, despite the vastly improved hygiene and relative opulence of to-day, the patients' chances of recovery are no longer hopeless, as they were nine times out of ten in those days-far from it, for there is often a choice of several treatments nowadays, all nearly equally effective.

That was a disease of older infants -6 to 18 months or so-a true "cholera infantum," though the cholera vibrio threw in its hand when its watery hiding-place was revealed in the "Broad Street pump" outbreak of 1854. To-day it is older children and adults who suffer most from intestinal infections and other disorders, among which ulceration ranks increasingly high. And though non-cancerous deaths are falling, with some disappointing exceptions, the functional disorders, many of them seriously disabling, are getting an upper hand. Nor are the infectious, or infective, catarrhs-those that attack the alimentary tract's mucous membranes-by any means overcome. We in Tonbridge, a country town of 20,000 inhabitants, with a famous boarding-plus-day public school for boys, have only lately been passing through a short but unpleasant example of (?) infective gastro-enteritis, and its cause remains unknown at the time of writing. Nevertheless, it illustrated well the snags of management-i.e., of keeping the symptoms under control till nature had worked a cure, with whichever chemical and physical aids the medical attendants favoured. For this was an ailment where recovery was as certain as anything can be in this uncertain world; and the doctors' main problems circled round that of, "Which drug firm shall we back? That famous and familiar one? Or one of the comparatively tiny but often deserving newer names, which sometimes make us think for ourselves?"

Having a colostomy myself, I can speak with feeling, if not with authority, about diarrhoea cures. And a resident household of three others, one a schoolboy, taught me much about sickness, in both senses, and about other aspects of diarrhoea. I came to a few solid conclusions, though statisticians may question their bases. For the sickness, it seemed, only a hot bottle or electric pad, or blankets heated before the fire, and a few sips of some fizzy sweetened drink, were worth their trouble (we'd have felt differently if faced with real dehydration, no doubt). But for the diarrhoea there are now some genuine and unobjectionable -even non-poisonous-medicaments; about four, if I may classify a bit. They are :

(1) Opiates.-Morphine $\frac{1}{4}$ gr. (16 mg.), perhaps repeated once but once only, may check the diarrhoea while vomiting is still being troublesome ; nothing (or hardly anything) else will, so this may be justifiable in the early stages; later on, a few minims of tinct. opii by mouth is surprisingly effective and leaves no bogy of -addiction (a much overrated spook, I know). Make it tinct. opii 3-5 min. $(0.2-0.3 \mathrm{ml}$.), kaolin $60 \mathrm{gr}$. (4 g.) ; aqua chlor. to the ounce $(28 \mathrm{ml}$.); for that may save the patient trouble with the poisons rulers. Otherwise I would not include kaolin among medicamenta vera.

(2) Sulphaguanidine.-Old-fashioned ? If so, incidentally so; for I am certain that this has a pharmacological binding action that "sulfasuxidine" and " sulfathalidine" have not got. It begins to bind, in fact, before it can have started killing off the pathogenic bacteria. Of this I have satisfied myself.

(3) Methyl cellulose, or "celevac," in granules, please ; for the tablet form does not work so well in most people. I am medical adviser to the English makers of this cellulose derivative, but I got the job because I had found the granules worked so well on me, and not the other way round. So, though I am biased, my opinion still holds water. These are taken with as little liquid as is practicable (one or two tablespoonfuls), and the dose is a drachm $(4 \mathrm{~g}$.) or two night and morning or more often if necessary.

(4) Aspirin.-Few people seem to remember the slight but definite constipating action of aspirin. It irritates the mouth and stomach, etc., yes ; but very slightly, and it does more good than harm, always provided you have no gastric or duodenal ulcer liable to bleed. If you have, try more celevac and keep far away from aspirin and all the salicylates, or it will bleed forthwith and for certain.-I am, etc.,

Tonbridge, Kent.

E. Clayton-Jones.

\section{Early Management of Poliomyelitis}

SIR,-Dr. E. G. Brewis in his article, "Early Management of Poliomyelitis" (Journal, June 30, p. 1539), makes a number of statements with which few, I imagine, of his colleagues engaged in the treatment of this disease would agree. In particular he writes that when the diagnosis of poliomyelitis becomes probable "there may be a natural desire on the part of the family doctor, aided by pressure from the relatives, to send the patient to hospital. This course must be firmly resisted ... hospital admission has nothing to offer the patient which cannot be done in the ordinary decent home. This should be emphasized because so often the parents .... and occasionally the doctor himself, believe that something can be done in hospital which may make all the difference to the patient's chances. In many instances the reverse is true" (the italics are mine).

Your contributor may be trailing his coat, or perhaps doffing his bonnet to give a bee an airing, but, if he is serious, may I say that I regard this as most dangerous and irresponsible advice? Polio is one of the most insidious and unpredictable of all diseases, and nobody can possibly foretell what will happen in any given case. In one, paralysis may spread from head to foot-or from foot to head-in 24 hours; in another, paralysis may appear in one limb and then come to a halt for a day or two, only to return with a devastating rush when all danger appears to be past. In a third it may spread steadily but slowly for a week. No two cases are alike, and the only confident prediction one can make is that as soon as the process has begun anything may happen.

In these circumstances it seems incredible that anyone should counsel delay in bringing the patient under skilled and continuous observation as soon as possible. Such delay is undoubtedly responsible for so many of the lamentable results in the treatment of bulbar and bulbo-spinal cases reported by your contributor and others. Far too many of these patients arrive in hospital already hopelessly compromised-half-drowned in their own secretions, or having vomited and inhaled the vomit. Even in hospital, unless constant supervision is exercised, bulbar paralysis in particular may elude detection until serious damage has occurred.

There is a further consideration. The gravest disability from which the recovered case can suffer is paralysis of respiration in whole or part. Many believe that this can be minimized by giving assistance to the threatened neurones at the earliest possible moment. As soon therefore as any detectable weakness of respiration or significant fall in vital capacity appears, the patient is put in a respirator in the hope that by taking the load off the intercostals and diaphragm more of their capacity may be retained than if the relevant neurones are allowed to reach the point of exhaustion before relief is afforded. Results would appear to justify this approach.

There are other statements which one receives with some surprise, as, for example, that "the physical stress of ambulance journeys ... may be a deciding factor in initiating paralysis." What evidence exists-or can possibly be adduced-to warrant such an assertion? But in any event, in direct contrast to Dr. Brewis, I would say to the family doctor: "As soon as you have made the diagnosis of poliomyelitis, and especially if paralysis has appeared, get him into hospital as soon as possible, for he is launched on a 